\title{
Qualidade bacteriológica de águas subterrâneas em cemitérios
}

\author{
Maria Therezinha Martins*, Vivian H. Pellizari*, Alberto Pacheco**, Débora M. Myaki*, \\ Cristina Adams*, Nelma R. S. Bossolan*, José M. B. Mendes**, Seiju Hassuda***
}

\begin{abstract}
MARTINS, M. T. et al. Qualidade bacteriológica de águas subterrâneas em cemitérios. Rev. Saúde públ., S. Paulo, 25: 47-52, 1991. Foram analisadas amostras de águas subterrâneas de três cemitérios localizados em áreas geologicamente distintas de São Paulo e de Santos, Brasil, com relação às condições higiênicas e sanitárias. Para as primeiras foram considerados os coliformes totais, bactérias heterotróficas, microrganismos proteolíticos e lipolíticos. Para as sanitárias foram pesquisados coliformes fecais, estreptococos fecais, clostrídios sulfito redutores, colifagos e salmonelas. Verificou-se que as águas não apresentaram condições higiênicas satisfatórias e, em alguns casos, foram encontrados níveis altos de nitrato $(75,7 \mathrm{mg} / \mathrm{l})$. A deteç̧ão de níveis mais elevados de estreptococos fecais e de clostrídios sulfito redutores em relação aos coliformes fecais, na maior parte das amostras, parece mostrar que os dois primeiros indicadores seriam mais adequados para avaliação das condições sanitárias deste tipo de água. Foi detectada Salmonella apenas em uma amostra e não foram detectados colifagos. $\mathrm{Na}$ análise estatística, foram encontradas correlaçōes significantes entre três indicadores de poluicão fecal assim como entre as contagens em placas de bactérias heterotróficas aeróbias, anaeróbias e lipolíticas. Foi observada uma relação direta entre a deterioração da qualidade da água $e$ as condições geológicas e hidrogeológicas do ambiente estudado, devendo este fator ser considerado para o planejamento e implantação de cemitérios.
\end{abstract}

Descritores: Águas subterrâneas, análise. Contaminação bacteriológica da água, análise. Práticas mortuárias.

\section{Introduçăo}

No Brasil, a proteção qualitativa das águas subterrâneas vem sendo negligenciada, apesar da sua grande importância do ponto de vista econômico e estratégico. É necessário, portanto, uma proteção contra as diferentes formas de contaminação das mesmas $^{21}$.

O solo tem um papel muito importante na retenção dos microrganismos, através de fatores físicos e químicos ambientais, que afetam a infiltração e o carreamento dos microrganismos em direção ao lençol freático. A implantação dos cemitérios, sem levar em consideração os critérios geológicos (características litológicas e estrutura do terreno) e hidrogeológicos (nível do lençol freático), constitui uma das causas de deterioração da qualidade das águas subterrâneas, pois substâncias e microrganismos provenientes de de-

* Departamento de Microbiologia do Instituto de Ciências Biomédicas da Universidade de São Paulo - Caixa Postal 4365 - 01051 - São Paulo, SP - Brasil.

* Centro de Pesquisas de Águas Subterrâneas (CEPAS). Departamento de Geologia Econômica e Geofísica Aplicada do Instituto de Geociências da Universidade de São Paulo - Caixa Postal 20899 - 01498 - São Paulo, SP Brasil.

*** Centro de Pesquisas de Águas Subterrâneas (CEPAS). Instituto Geológico - Caixa Postal 8772 - 01000 - São Paulo, SP - Brasil. composição de cadáveres podem ter acesso às mesmas, representando um risco do ponto de vista sanitário e higiênico. Mulder (1954) apud Bower ${ }^{6}$, (1978), registrou alguns casos históricos sobre a contaminação das águas subterrâneas, que se destinavam ao consumo humano, por líquidos humorais (provenientes da decomposição dos corpos). Existe ainda o problema da ocupação das áreas próximas aos cemitérios por populações de baixa renda que podem estar utilizando esta água através da instalação de poços ${ }^{21}$.

No estudo das águas subterrâneas desses locais, os parâmetros microbiológicos têm um papel de destaque. Do ponto de vista de saúde pública, os aspectos sanitários devem ser enfocados estudando o comportamento dos indicadores de poluição de origem fecal bem como de bactérias patogênicas.

Os indicadores de poluição mais comumente utilizados são os coliformes, principalmente o grupo dos coliformes fecais ou termotolerantes e os estreptococos fecais ${ }^{16}$.

Os coliformes fecais têm sido um dos indicadores de uso mais freqüente na avaliação da qualidade de água. Um dos problemas da utilização deste grupo como indicador de patógenos entéricos é que ele possui um menor tempo de sobrevivência no solo e em águas subterrâneas, do que alguns destes patógenos. Contudo, a maior vantagem é que os coliformes fecais não têm demonstrado condições de desenvolvimento no meio aquático, 
diferindo dos coliformes totais, e sobrevivem tempo suficiente para ser um indicador útil ${ }^{5}$.

Os estreptococos fecais também são excretados nas fezes humanas, embora em quantidade inferior a E.coli, mas podem sobreviver por tempo maior em águas subterrâneas mantidas naturalmente em temperaturas baixas ${ }^{9,12}$.

Alêm desses, outros indicadores têm sido propostos para avaliação da qualidade das águas.

Os clostrídios sulfito redutores são bactérias formadoras de esporos sendo, portanto, mais resistentes às condiçðes ambientais adversas, permanecendo por longo período de tempo no solo. Por esses motivos são indicadores de poluição remota ${ }^{8}$.

Os colifagos são vírus que parasitam bactérias do grupo coliforme, podendo ser utilizados como indicadores indiretos da presença de microrganismos patogênicos e já foram relacionados, em outras pesquisas, com a possível presença de enterovírus nas amostras estudadas ${ }^{11,13}$.

Para evidenciação do risco da presença de microrganismos patogênicos nas águas subterrâneas tem sido também utilizada a determinação de Samonella, pois neste gênero, encontram-se bactérias responsáveis pela febre tifóide e por infecçסes gastro-intestinais de grande importância para a saúde pública ${ }^{10}$.

Para avaliação das condições higiênicas têm sido propostos os coliformes totais e as bactérias heterotróficas aeróbias ${ }^{19}$. Normalmente não têm sido utilizados outros possiveis indicadores da presença de matéria orgânica, como proteínas e lipídeos, em água. No entanto, as bactérias proteolíticas e lipolíticas são comumente estudadas na microbiologia de alimentos, como decompositores de carnes e outros produtos de origem animal ${ }^{1,17}$.

Numa revisão intensiva da literatura nacional e internacional, sobre o impacto dos cemitérios na qualidade de águas subterrâneas, do ponto de vista microbiológico, nada foi encontrado a respeito.

Este trabalho objetivou a avaliação da qualidade sanitária e higiênica de águas subterrâneas de três cemitérios das regiões da Grande São Paulo e Baixada Santista, bem como estudar a possivel interferência das condiçz̃es geológicas dos terrenos e a altura do lençol freático, na qualidade dessas águas.

\section{Material e Método}

Um total de 67 amostras oriundas de três cemitérios localizados na Grande São Paulo foram analisadas no período de janeiro a dezembro de 1989. Destas amostras, 29 foram do Cemitério da Vila Formosa (CVF); 11 do Cemitério de Vila Nova Cachorinha (CVNC) na cidade de São Paulo, e 27 do Cemitério de Areia Branca (CAB), na
Baixada Santista. Os principais critérios utilizados na escolha das necrópoles foram os aspectos geológicos e hidrogeológicos. Procurou-se selecionar áreas com características geológicas distintas para se avaliar o tipo de resposta ao processo de poluição do lençol freático, em função da litologia. Os pontos de amostragem foram escolhidos com base em estudos geofísicos prévios tais como: o método da eletrorresistividade, através do procedimento da sondagem elétrica, e o método eletromagnético indutivo, através de caminhamentos eletromagnéticos, realizados pelo Instituto de Geociências da Universidade de São Paulo.

Nos pontos escolhidos foram instalados piezômetros, constituídos por tubos de PVC de 3 polegadas de diâmetro, com ranhuras horizontais de $2 \mathrm{~mm}$ de espessura no último metro. A porção ranhurada do tubo foi envolta com tela de material inerte, de forma a reduzir o espaço das ranhuras. $O$ espaço anular entre o tubo e o furo foi prenchido com cascalho, até cobrir as ranhuras, servindo como pré-filtro. Acima dele, colocou-se o próprio material retirado do tubo e, na superfície ao redor da boca do mesmo, foi construída uma laje de concreto com a função de selo sanitário.

As amostras foram coletadas em frascos de plástico, não tóxico, de 5 litros e estéreis, de acordo com "Standard Methods for the Examination of Water and Wasterwater"3 e com o auxilio de um tubo coletor metálico, lavado e desinfetado previamente antes de cada coleta feita nos piezômetros.

Os microrganismos escolhidos para este estudo foram representantes dos indicadores de poluição fecal, de um patógeno, além de dois grupos de bactérias decompositoras de matéria orgânica que participam do processo de decomposição dos corpos, utilizadas para verificar se os microrganismos estão sendo carreados dos túmulos para as águas. A contagem padrão de bactérias anaeróbias (CPH 2) e aeróbias (CPH 1) também foi realizada.

As amostras foram, portanto, submetidas aos seguintes testes bacteriológicos:

a - Técnicas de Tubos Múltiplos para determinação de:

- coliformes totais (CT) - segundo APHA ${ }^{3}, 16^{a}$ ed.

- coliformes fecais (CF) - segundo APHA ${ }^{3}, 16^{4} \mathrm{ed}$.

- estreptococos fecais (EF) - segundo $\mathrm{APHA}^{3}$ $16^{\mathrm{a}} \mathrm{ed}$.

- clostrídios sulfito redutores (CSR) - segundo

"The Bacteriological Examination of Water Supplies"4.

- bactérias proteolíticas (PROT) - para a deteç̧ão desta bactéria foi utilizado um meio de cultura composto por caldo nutriente contendo $12 \%$ de gelatina ${ }^{22}$. Foram utilizadas séries de cinco tubos para cada diluição de amostra que foram incubados a $35^{\circ}+/-0,5^{\circ} \mathrm{C}$ por 48 horas. Para verificar 
se houve atividade proteolítica, indicada pela liquefação da gelatina, os tubos foram colocados em geladeira durante duas horas e em seguida, examinados.

b - Contagem Padrão de Bactérias Heterotróficas Aeróbias (CPH1) segundo APHA ${ }^{3}, 16^{\mathrm{a}} \mathrm{ed}$.

c - Contagem Padrão de Bactérias Heterotróficas Anaeróbias (CPH2) - adaptação do $\mathrm{CPH}$, através da incubação das placas em jarras de anaerobiose, por 48 horas.

d - Pesquisa de Salmonella - Cinco litros de cada amostra foram filtrados em membrana filtrante $0,45 \mu \mathrm{m}$ (Millipore) que foi colocada em erlenmeyer contendo $200 \mathrm{ml}$ de caldo selenito (Difco) adicionado de novobiocina e este foi incubado por cinco dias a $42,5+/-0,2^{\circ} \mathrm{C}$. No primeiro, segundo e quinto dias, o material foi repicado para placas de agar xilose-lisina-desoxicolato (Difco), agar sulfito-bismuto (DifCo) e agar verde brilhante (Difco) e incubadas por 24 horas a $35,0+/-0,5^{\circ} \mathrm{C}$. As colônias típicas foram repicadas para meio EPM-MILI (Probac) e, quando o resultado foi compatível para o gênero Salmonella, foi feita a sorologia utilizando anti-soros somáticos e flagelar polivalentes (Probac). Foram analisadas 44 amostras.

e - Pesquisa de Colifagos - segundo Isbister e col. ${ }^{15}$ tendo sido analisadas 45 amostras .

f - Pesquisa de Bactérias Lipolíticas (LIPO) segundo Alford ${ }^{1}$.

\section{Resultados e Discussão}

Os três cemitérios estudados encontram-se em regiōes geologicamente bem conhecidas. No CVF, há predomínio de sedimentos terciários da Bacia de São Paulo, onde ocorre alternância de solos argilosos e areno-argilosos. O CVNC, localiza-se em terreno predominantemente arenoso, com niveis mais argilosos. No $C A B$ há predomínio de sedimentos quatemários marinhos que são arenosos, com alta porosidade e permeabilidade.

Com relação às características hidrogeológicas verificou-se que, no CVNC, o nivel d'água variou entre 4 e 9 de profundidade, o que caracteriza a existência de um aquífero suspenso. Este tipo de aquífero também foi encontrado no CVF, onde o nível do lençol freático variou entre 4 e $12 \mathrm{~m}$. No $\mathrm{CAB}$, localizado em área plana, o nível de água foi encontrado numa profundidade que variava de 0,60 a 2,20m e era influenciado, pelo regime de marés.

Estas diferenças geológicas e do nível do lençol freático, influenciaram na qualidade bacteriológica das águas estudadas.

O solo arenoso, que possibilita uma permeabilidade maior e o nivel do lençol freático de pequena profundidade encontrados no $\mathrm{CAB}$ poderiam favorecer a passagem de bactérias do solo e dos túmulos para as águas subterrâneas. Isto poderia explicar os maiores niveis de CF, EF, CSR, de bactérias heterotróficas aeróbias e de bactérias lipolíticas, nesse cemitério (Tabela 1 ) em relação aos demais. Neste tipo de terreno, parece haver uma condição de aerobiose, (que pode ser verificada pela quantidade elevada de bactérias heterotróficas aerobias) e passagem de matéria orgânica para o lençol freático, onde as proteínas seriam convertidas a nitrato, que se acumula nessas águas.

No CVNC (Tabela 1) foi observada uma elevada quantidade de bactérias heterotróficas anaeróbias, caracterizando uma condição de anaerobiose, havendo um favorecimento da desnitrifi-

Tabela 1. Valores máximos, minimos e média geométrica (MG) dos diferentes indicadores bacteriológicos, em amostras de águas dos três cemitérios estudados

\begin{tabular}{|c|c|c|c|c|c|c|c|c|c|}
\hline \multirow[t]{2}{*}{ Indicadores" } & \multicolumn{9}{|c|}{ Cemitérios } \\
\hline & máx. & $\min$ & MG & máx. & $\min$. & MG & máx. & $\min$. & MG \\
\hline$C T$ & $>1,6 \times 10^{3}$ & $<2$ & 58 & $>1,6 \times 10^{3}$ & $<2$ & 14 & $>1,6 \times 10^{3}$ & 27 & $1,6 \times 10^{2}$ \\
\hline CF & $1,6 \times 10^{3}$ & $<2$ & 5 & $3,0 \times 10^{2}$ & $<2$ & 3 & 7 & $<2$ & 2 \\
\hline$E F$ & $>1,6 \times 10^{3}$ & $<2$ & 55 & $1,6 \times 10^{3}$ & $<2$ & 8 & $1,6 \times 10^{3}$ & $<2$ & 8 \\
\hline $\begin{array}{l}\text { CSR } \\
\text { PROT }\end{array}$ & $\begin{array}{l}>1,6 \times 10^{3} \\
>1,6 \times 10^{3}\end{array}$ & $\begin{array}{l}<2 \\
23\end{array}$ & $\begin{array}{c}21 \\
4.3 \times 10^{2}\end{array}$ & $\begin{array}{r}2,4 \times 10^{2} \\
>1,6 \times 10^{3}\end{array}$ & $\begin{array}{l}<2 \\
<2\end{array}$ & $\begin{array}{c}14 \\
2.7 \times 10^{2}\end{array}$ & $\begin{array}{c}27 \\
9.0 \times 10^{3}\end{array}$ & $\stackrel{2}{2} 2 \times 10^{2}$ & $\begin{array}{c}7 \\
1.0 \times 10^{3}\end{array}$ \\
\hline $\mathrm{CPH} 1$ & $8,1 \times 10^{6}$ & $7,0 \times 10^{2}$ & $1,5 \times 10^{4}$ & $7,1 \times 10^{5}$ & $2,0 \times 10^{2}$ & $9,0 \times 10^{3}$ & $5,3 \times 10^{4}$ & $2,8 \times 10^{3}$ & $1,1 \times 10^{4}$ \\
\hline $\begin{array}{l}\text { CPH2 } \\
\text { LIPO }\end{array}$ & $\begin{array}{l}3,8 \times 10^{5} \\
1,2 \times 10^{6}\end{array}$ & $\begin{array}{l}<2 \\
80\end{array}$ & $\begin{array}{r}4,0 \times 10^{9} \\
6,4 \times 10^{3}\end{array}$ & $\begin{array}{l}1,2 \times 10^{3} \\
1,5 \times 10^{3}\end{array}$ & $\begin{array}{c}1,3 \times 10^{2} \\
75\end{array}$ & $\begin{array}{l}6,7 \times 10^{2} \\
2,5 \times 10^{3}\end{array}$ & $\begin{array}{l}1,6 \times 10^{5} \\
3,6 \times 10^{4}\end{array}$ & $\begin{array}{l}4,4 \times 10^{2} \\
1,6 \times 10^{2}\end{array}$ & $\begin{array}{l}1,6 \times 10^{4} \\
3,9 \times 10^{3}\end{array}$ \\
\hline
\end{tabular}

- CT -coliformes totais; CF - coliformes fecais; EF - estreptococos fecais; CSR - clostridios sulfito redutores; PROT bactérias proteoliticas; CPH 1 - contagem padrão de bactérias heterotróficas aeróbias; CPH 2 - contagem padrão de bactérias heterotróficas anaeróbias; LIPO - bactérias lipolíticas. 
cação do nitrato que é levado a nitrogênio, baixando, portanto sua concentração.

Pela análise da Tabela 1, verifica-se que no CVF foram encontrados os niveis mais baixos de $\mathrm{CT}, \mathrm{EF}$, bactérias proteolíticas, contagem padrão de bactérias aeróbias e anaeróbias bem como de bactérias lipolíticas, o que indicaria que este tipo de região geológica, onde há alternância de solos argilosos e areno-argilosos, serviria como um filtro natural, retendo os microrganismos e a matéria orgânica no solo. Havendo pouca matéria orgânica nas águas, a quantidade de material nitrogenado também seria pequena, o que poderia explicar a baixa detecção de nitrato nestas águas.

Apesar dos menores niveis de indicadores encontrados no CVF, os resultados encontrados quanto aos índices de poluição de origem fecal (com exceção de colifagos) e dos organismos utilizados como indicadores de presença de matéria orgânica, mostraram que as condiçōes higiênicas e sanitárias das águas estudadas foram insatisfatórias para os três cemitérios.

A deteç̧ão de EF e CSR, na maioria das amostras, e a ausência de CF em muitas destas, parece mostrar que estes dois indicadores seriam mais adequados para avaliação de águas subterrâneas do ponto de vista sanitário, o que está de acordo com os resultados encontrados por Alhajjar e col. ${ }^{2}$ e de Geldreich ${ }^{12}$, quanto a EF. No entanto, não se deve descartar a hipótese de que algumas das espécies presentes nesses grupos seriam microrganismos causadores do processo de putrefação, como por exemplo, as espécies dos gêneros
Streptococcus e Clostridium ${ }^{14}$.

Não foram detectados colifagos em nenhuma das 45 amostras de águas coletadas nos três cemitérios. Isto pode ser explicado pelo fato destes vírus adsorverem mais facilmente às particulas do solo do que as bactérias, não sendo carreado até 0 lençol fréticico ${ }^{20}$.

Foram analisadas 44 amostras para determinação de Salmonella, sendo que este patógeno só foi detectado uma vez, no CVF.

$\mathrm{Na}$ análise estatística entre os indicadores estudados, considerando os dados totais dos três cemitérios (Tabela 2) foram observadas correlações significantes $(p<0.001 ; p<0.01$ e $p<0.02)$ entre os três indicadores de poluição fecal, bem como entre as contagens de bactérias heterotróficas aeróbias e anaeróbias e contagem de bactêrias lipolíticas.

As bactérias lipolíticas (LIPO) e proteolíticas (PROT) estão relacionadas com o processo de decomposição da matéria orgânica animal e vegetal. Os resultados de análise por nós realizadas préviamente em poços limpos, revelam que estes tipos de microrganismos eram encontrados em baixa quantidade ou ausentes. Como níveis elevados destas bactérias foram detectados nas águas subterrâneas dos três cemitérios, provavelmente elas são oriundas do processo de decomposição dos corpos pois, durante o mesmo, ocorre uma proliferação de microrganismos que poderiam contaminar as águas.

Com relação ao nível de nitrato, a Organização Mundial de Saúde ${ }^{23}$, bem como a Portaria $n^{2} 36 /$ GM de 19/01/90 do Ministério da Saúde ${ }^{18}$ reco-

Tabela 2. Matriz de correlaçăo entre os indicadores analisados, considerando os dados totais das amostras de águas provenientes dos trés cemitérios estudados.

Indicadores

\begin{tabular}{cccccccc} 
Indicadores & $C T$ & $C F$ & $E F$ & CSR & PROT & CPH1 & CPH2 \\
\hline C F & $0,387^{* *}$ & & & & & \\
E F & $0,527^{*}$ & $0,288^{* * *}$ & & & & & \\
CSR & $0,323^{* *}$ & $0,807^{*}$ & $0,335^{* *}$ & & & & \\
PROT & 0,063 & $-0,060$ & 0,102 & $-0,070$ & & \\
CPH1 & $-0,038$ & $-0,038$ & 0,016 & 0,086 & 0,046 & \\
CPH2 & $-0,099$ & $-0,083$ & 0,148 & 0,056 & 0,002 & $0,295^{* * *}$ & \\
UPO & $-0,052$ & $-0,014$ & 0,038 & 0,119 & 0,007 & $0,789^{*}$ & $0,698^{*}$
\end{tabular}

*p<0,001 *** $p<0,0102$

CT - coliformes totais; CF - coliformes fecais; EF - estreptococos fecais; CSR - clostridios sulfito redutores; PROT - bactérias proteolíticas; $\mathrm{CPH} 1$ - contagem padrăo de bactérias heterotróficas aeróbias; $\mathrm{CPH} 2$ - contagem padrăo de bactérias heterotróficas anaeróbias; LIPO - bactérias lipoliticas. 
mendam o valor máximo de $10 \mathrm{mg}$ de $\mathrm{NO}_{3}$ /litro, pois uma concentração superior pode ocasionar a metahemoglobinemia infantil.

Apesar do nitrato não ter sido detectado no CVF, ele foi encontrado no $C A B$ numa concentração variando entre 0,48 e $75,70 \mathrm{mg} /$ litro e no CVNC $(0,04-2,10 \mathrm{mg} /$ litro). Verifica-se, portanto, que a concentração deste composto foi muito elevada em alguns pontos. Quanto à concentração mais baixa desta substância nas amostras do CVNC pode ser explicada pela condição de anaerobiose, criada no terreno mais argiloso que acumula água. Estas condições anaeróbias favorecem a redução do nitrato à amônia ou sua desnitrificação, pela ação microbiana?

A análise dos dados obtidos no presente estudo revela que o nível do lençol freático e as condições geológicas do terreno exercem papel importante na qualidade bacteriológica das águas subterrâneas que, no caso dos cemitérios, sofrem riscos de contaminação. Portanto, as normas para construção de cemitérios deveriam levar em consideração estas condições, assim como o código sanitário de 1978 deveria também ser revisto, considerando este aspecto.

MARTINS, M. T. et al. [Bacteriological quality of groundwater in cemiteries]. Rev. Saúde públ., S. Paulo, 25: 47-52, 1991. Groundwater samples collected by piezometers from three cemiteries in geologically distinct areas of S. Paulo and Santos, Brazil, were analysed in order to determine their hygienic and sanitary conditions. Fecal coliformes, fecal streptococci, sulfite reducer clostridia and Salmonella were searched for the purpose of evaluating sanitary conditions, and total coliforms, heterotrophic bacteria, proteolitic and lipolitic microorganisms for evaluating hygienic conditions. In some samples, nitrate levels were also determined. It was discovered that these waters do not present adequate sanitary and higienic conditions and that in some cases, nitrate levels were extremelly high (75.7 $\mathrm{mg} / \mathrm{l})$. In most samples, higher levels of fecal streptococci and sufite reducer clostridia than fecal coliforms were detected, which seems to show that the two former indicators would be more appropriate for evaluating the sanitary conditions of this kind of water. Salmonella were detected in only one of 44 samples analysed and coliphages in none. In the stastistical analysis, the correlation matrix showed significant correlations among three fecal pollution indicators, as well as among anaerobic and aerobic heterotrophs and lipolitic bacteria. A direct relationship between the deterioration of water quality and the geological and hydrogeological conditions of the environment studied was observed. When cemiteries are constructed these conditions should, therefore, be taken into consideration.

Keywords: Ground water, analysis. Bacteriological water contamination. Mortuary practices.

\section{Referências Bibliográficas}

1. ALFORD, J. A. Lipolytic microorganisms . In: Speck, M. L. Compedium of methods for the microbiological of foods. Washington, D.C., American Public Health, 1976. p.184-8.

2. ALHAJAR, B. J.; STRAMER, S. L.; CLIVER, D. O.; HARKIN, J. M. Transport modelling of biological tracers from septic systems. Wat. Res., 22: 907-15, 1988.

3. AMERICAN PUBLIC HEALTH ASSOCIATION. Standard methods for the examination of water and waste. water. $16^{\text {th }}$ ed. New York, 1985.

4. THE BACTERIOLOGICAL examination of water supplies; Reports on Public Health and Medical Subjects. London, Her Majesty's Stationary Office, 1969. p. 323.

5. BARROW, G. I. Bacterial indicators and standards of water quality in Britain. In: Hoadley, A. W. \& Dutka, B. J. Bacterial indicators, health hazard associated with water, ASTM STP 635. Philadelphia, American Society for Testing and Materials, 1977. p. 289-336.

6. BOWER, H. Ground water hydrology. New York, McGraw Hill, 1978.

7. BULGER, P. R.; KEHEW, A. E.; NELSON, R. A. Dissimilatory nitrate reduction in a waste-water contaminated aquifer. Ground Water, 27: 664-71, 1989.

8. CABELLI, V.J . Clostridium perfringens as a water quality indicator. In: Hoadley, A. W. \& Dutka, B. J. Bacterial indicators, health hazards associated with water, ASTM STP 635. Philadelphia, American Society for Testing and Materials, 1977. p. 65-79.

9. CLAUSEN, E. M.; GREEN, B. L.; WARREN, L. Fecal Streptococci: indicators of pollution. In: Hoadley, A. W. \& Dutka, B. J. Bacterial indicators, heatlh hazards associated with water, ASTM STP 635. Philadelphia, American Society for Testing and Materials, 1977. p. 247-64.

10. DUTKA, B. J. \& BELL, J. B. Isolation of Salmonella from moderately polluted waters. J. Wat. Pollut. conirol Fed., 45: 316-23, 1973.

11. DUTKA, B. J.; EL-SHAARAWI, A.; MARTINS, M. T.; SANCHEZ, P. S. North and South American studies on the potential of the coliphage as a water quality indicator. Wat. Res., 21: 1107-25, 1987

12. GELDREICH, E. E. Applying bacteriological parameters to recreational water quality. J. Amer. Wat. Wks. Ass., 62: 113-20, 1970.

13. GRABOW, W.O K.; COUBROUGH, P.; NUPEN, E. M.; BATEMANN, B. M. Evaluation of coliphage as indicator of the virological quality of sewage polluted waters. Waters S. Afr.., Pretoria, 10: 7-14, 1984.

14. INGRAM, M.; SLMONSEN, B. Meats and meats products. In: Intemational Commission on Microbiological Specifications for Foods. Microbial ecology of foods. New York, Academic Press, 1980. p. 333 . 407.

15. ISBISTER, J. D.; SIMMONS, J. A.; SCOTT, W. M.; KITCHENS, J. F. A simplified method for coliphage detection in natural waters. Acta microbiol. polon., 32: $197,1983$.

16. KOTT, Y. Current concepts of indicator bacteria. In: Hoadley, A. W. \& Dutka, B. J. Bacterial indicators, health hazards associated with water, ASTM STP 635. Philadelphia, American Society for Testing and Materials, 1977. p. 3-13.

17. LEE, J. S. Proteolytic microorganisms. In: Speck, M. L. Compedium of methods for the microbiological exam. ination of foods. Washington, D.C., American Public 
Health Association, 1976. p. 184-8.

18. MINISTÉRIO DA SAUDE. Portaria 36/GM de 19 de Janeiro de 1990: Dispãe sobre normas e padrão de potabilidade de água destinada ao consumo humano. Diário Oficial da Uniso, Brasília, 23 jan. 1990. p. $12-19$

19. MOSSEL, D. A. A. \& GARCIA, B. M. Microbiologia de los alimentos . Zaragosa, Editorial Acribia, 1985. p. 373.

20. OHGAKI, S.; KETRATANAKUL, A.; SUDDEVGRAI, S.; PRASERTSON, V.; SUTHIENKUL, O. Adsorption of coliphages to particulates. Wat. Sci. Technol., 18: 267-75, 1986.

21. PACHECO, A. Os cemitérios como risco potencial para as águas de abastecimento. Rev. SPAM, 17: 25-37,1986.

22. VERA, H. D. \& DUMOFF, M. Culture media. In: Lennette, E. H.; Spaulding, E. H.; Truant, J. P. Manual of clinical microbiology. Washington, D.C., American Society for Microbiology, 1974. p. 881-929.

23. WORLD HEALTH ORGANIZATION. Guidelines for drinking water quality: health criteriz and other supporting information. Geneva, 1984. v. 2.

Recebido para publicaçāo em $7 / 6 / 1990$ Reapresentado em 19/10/1990 Aprovado para publicaçäo em $27 / 10 / 1990$ 